\title{
Os diferentes sentidos das representações dos objetos matemáticos \\ e as atividades de tratamento e conversão entre registros
}

\author{
The different meanings of representations of mathematical objects and \\ activities of processing and conversion of records
}

Karen Hyelmager Bariccatti

karenhg@utfpr.edu.br

Rodolfo Eduardo Vertuan

rodolfovertuan@yahoo.com.br

\begin{abstract}
Resumo
A presente pesquisa objetiva discutir os diferentes sentidos das representações de estudantes do Ensino Médio, a partir de uma questão da prova da Olimpíada de Matemática das Escolas Públicas, referente ao ano de 2010. A diversidade de registros escritos foi analisada, ainda em relação as atividades de tratamento e de conversão entre diferentes registros de representação semiótica. Neste contexto, verifica-se que a conversão entre registros, presente em algumas resoluções, denota criatividade dos alunos, os quais, por utilizarem diferentes registros de um mesmo conceito matemático, potencializam a aprendizagem deste conceito, bem como a diferenciação entre o objeto matemático representado e a representação em si.
\end{abstract}

Palavras-chave: Sentido. Registros de Representação Semiótica. Objeto matemático.

\begin{abstract}
This paper aims to discuss the different meanings of the representations ofhigh school students, as a matter of proving Mathematics Olympiad Public Schools for the year 2010. The diversity of written records was analyzed also in relation to the activities of processing and conversion between different registers of semiotic representation. In this context, it appears that the conversion between records, present in some resolutions, denotes students' creativity, which, by using different registers of the same mathematical concept, enhance the learning of this concept, as well as the differentiation between the mathematical object represented and the representationitself.
\end{abstract}

Keywords: Sense. Semiotic Representation Registers. Mathematical object. 


\section{Introdução}

Entender a aprendizagem em Matemática como um processo que depende essencialmente da pessoa que aprende e das relações que ela estabelece entre conceitos e representações, implica, necessariamente, mudanças do paradigma existente de um ensino voltado à repetição para um paradigma voltado à análise, reflexão e construção de conhecimentos. Para Gálvez (1996),

[...] trata-se de colocar os alunos diante de uma situação que evolua de forma tal, que o conhecimento que se quer que aprendam seja o único meio eficaz para controlar tal situação. A situação proporciona a significação do conhecimento para o aluno, na medida em que o converte em instrumento de controle dos resultados de sua atividade. $\mathrm{O}$ aluno constroi, assim, um conhecimento contextualizado, em contraste com a sequenciação escolar habitual, onde a busca das aplicações dos conhecimentos antecede a sua apresentação, descontextualizada (p.33).

Neste contexto, o professor tem participação decisiva. Ele convida os alunos para realizarem a atividade e realiza a mediação da mesma, de modo a provocar a investigação e reflexão dos alunos em torno das decisões e ações que praticam. Oportuniza situações novas e desafiadoras, em que múltiplos saberes estão envolvidos.

Diante dessas situações novas e desafiadoras, muitas vezes os conhecimentos já adquiridos pelo aluno mostram-se insuficientes para enfrentar essas situações. $\mathrm{O}$ aluno, então, utiliza de seus conhecimentos anteriores, submete-os à revisão, modifica-os, rejeita-os, completa-os, redefine-os ou descobre novos contextos de utilização. Para Brousseau (1986), é nesse momento que os diferentes sentidos do conhecimento matemático podem ser definidos

[...] não somente pelo conjunto de situações em que este conhecimento é realizado como teoria matemática, não somente pelo conjunto de situações em que o sujeito o encontrou como meio de solução, mas também pelo conjunto de concepções que rejeita, de erros que evita, de economias que retoma (p. 56).

É importante a investigação por meio de diversas situações e análises de diferentes procedimentos dos alunos, quando diferentes representações simbólicas estão presentes. Um exemplo é o campo conceitual das estruturas multiplicativas, que consiste, em todas as situações que podem ser analisadas, como problemas de proporções simples e múltiplas, para os quais geralmente é necessária uma multiplicação, uma divisão ou uma combinação das operações. Para Vergnaud (1988, 1990), nesse campo conceitual da multiplicação, ainda estão presentes conceitos matemáticos como função linear, não linear, espaço vetorial, análise dimensional, fração, razão, taxa, número racional, entre outros. Analogamente, o campo 
conceitual das estruturas aditivas é o conjunto de situações que envolvem adições, subtrações ou a combinação de tais operações.

Pela análise dos diferentes procedimentos utilizados pelas crianças, por exemplo, na resolução de adições, Vergnaud (1996) percebe que as propriedades associativa e comutativa funcionam de maneira implícita e são, portanto, "teoremas em ato" (p.47). A noção de "teorema em ato" é expressa pela seguinte formulação: é uma proposição que é considerada como verdadeira por um sujeito individual para uma certa categoria de situações variáveis. Os alunos conhecem em ato as propriedades comutativa e associativa da adição e aplicam-nas em situações como: $5+21(5+1+20=6+20=26)$, buscando diferentes sentidos para suas realizações.

O sentido é uma relação do sujeito com as situações e os significantes. Mais precisamente, são os esquemas, isto é, os comportamentos e sua organização. O sentido da adição para um sujeito individual é o conjunto de esquemas que pode ser colocado em prática para tratar as situações que são enfrentadas e que implicam a ideia de adição, é também o conjunto de esquemas que pode ser colocado em prática para operar sobre os símbolos numéricos, algébricos, gráficos e da linguagem que representam a adição (VERGNAUD, 1991, p. 68).

Coaduna-se com essas reflexões Panizza (2006), quando ressalta que o professor, ao reconhecer esses conhecimentos em ato nos alunos, começa a visualizar o papel fundamental que possui no processo de aprendizagem dos conceitos, dos algoritmos e das representações convencionais de seus alunos. Ele pode partir dos conhecimentos que os alunos possuem e planejar intencionalmente oportunidades para que eles mostrem representações e procedimentos não convencionais, estabeleçam a validade dos mesmos, analisem os que são pertinentes, abandonem uns, escolham outros. Disso, decorre que os professores abandonem a “ilusão pedagógica”, termo designado por Vergnaud (1990, p.22), quando descreve a atitude do professor que acredita que o ensino consiste na apresentação organizada, clara, rigorosa das teorias formais e, tão logo tais medidas sejam tomadas, os alunos quase que imediatamente aprendem.

Para Panizza (2006), existem posturas didáticas diferentes no trabalho com alguns conceitos matemáticos e com as representações dos algoritmos convencionais de cálculo. Os conceitos matemáticos, como o sistema numérico, por exemplo, são trabalhados visando uma concepção construtiva do conhecimento, enquanto os sistemas simbólicos são considerados numa vertente empirista. Assim, o sistema educacional não considera a dificuldade dos alunos para efetuarem as operações, e mantém o objetivo único de ensinar os conteúdos mais difíceis 
aos alunos: os algoritmos convencionais de cálculo, por meio de treinos e busca de memorização de como se faz para dividir ou multiplicar, por exemplo.

Segundo a autora (2006, p.30), falta integrar à sala de aula os resultados de pesquisas que mostrem propostas didáticas e apresentem uma hipótese construtiva em relação aos aspectos da educação matemática de forma geral, de conceitos e de algoritmos convencionais, "uma vez que identificam processos de aprendizagem mediante os quais ambos participam dialeticamente um do outro". Outra posição que o sistema escolar veicula, de acordo com Panizza (2006), e que precisa ser revista, é a concepção segundo a qual resolve-se um problema compreensivelmente - raciocinando e utilizando conceitos, ou resolve-se o problema mecanicamente - operando sobre símbolos. A possibilidade de ter acesso automaticamente a um conhecimento não depende de sua natureza (conceitual ou simbólica), mas do nível de conhecimento no qual a pessoa se situa ao enfrentar a situação problema. Dificilmente, em fases iniciais de aprendizagem, os mecanismos ou os conceitos estão disponíveis na mente de forma automática. Isto será possível após a compreensão desses conceitos, a testagem de hipóteses pelos alunos, a repetição de mecanismos que são considerados mais adequados e a possibilidade de tratamento e conversão entre registros de representação simbólica.

\section{O tratamento e a Conversão entre Registros de Representação Semiótica}

Para Duval (2003), compreender um conceito matemático implica a capacidade de diferenciar o objeto matemático da representação que o torna acessível. Para o autor, “[...] os objetos matemáticos, começando pelos números, não são objetos diretamente perceptíveis ou observáveis com a ajuda de instrumentos" (p.14) e o acesso aos objetos matemáticos acontece por meio da utilização de uma representação. Neste sentido, Damm (1999) diz que “[...] não existe conhecimento matemático que possa ser mobilizado por uma pessoa, sem o auxílio de uma representação" (p.137).

Dentre as diferentes representações, Duval (2003) denominou de semióticas aquelas produções constituídas pelo emprego de signos pertencentes a um sistema de representação, os quais têm suas dificuldades próprias de significado e de funcionamento, tais como a escrita em língua natural, a escrita algébrica e os gráficos cartesianos.

Além do papel de comunicação, o modo como os alunos lidam com as representações semióticas influenciam sua compreensão do conceito matemático representado. Neste 
contexto, surge o termo "registros de representação semiótica", o qual é usado para designar os diferentes tipos de representação semiótica. As representações como língua natural, tabular, gráfica, figural e algébrica são exemplos de tipos diferentes de registros de representação. Cada uma delas consiste num registro de representação diferente (ou sistema de representação).

Para ser considerado um registro de representação, um sistema de signos precisa permitir três atividades cognitivas: a formação de uma representação identificável, o tratamento de um registro de representação e a conversão de um registro de representação para outro (DUVAL, 2003).

Dizemos que uma representação é identificável quando é possível evidenciar nela o que está apresentado. No caso da Matemática, o objeto matemático que representa. Para isso, o sistema de signos precisa ser comum a todas as pessoas, ou seja, ser estabelecido socialmente.

O tratamento de uma representação consiste na transformação desta em outra pertencente ao mesmo registro de partida. $\mathrm{O}$ tratamento é, portanto, uma mudança interna a um registro.

A conversão, por sua vez, consiste na transformação da representação de um objeto matemático em uma representação em outro registro, ou seja, consiste em mudanças externas ao registro do que está representado de partida.

É importante não confundir os processos de conversão com os de tratamento, pois "a conversão exige do sujeito o estabelecimento da diferença entre significado e significante" (DAMM, 1999, p.147), ou seja, entre o conceito matemático representado e o símbolo utilizado para representá-lo.

A conversão é um passo fundamental no trabalho com representações semióticas, pois a transformação de um registro em outro, conservando a totalidade ou uma parte do objeto matemático que está sendo representado, não pode ser confundida com o tratamento (DAMM, 1999, p.147).

Para Jahn e Karrer (2004), o número de registros mobilizados e relacionados no estudo de um objeto matemático influencia na possibilidade de compreensão deste objeto pelo aluno:

[...] a aprendizagem de um conceito matemático consiste em desenvolver coordenações progressivas entre vários sistemas de representação semiótica. [...] Desta forma, na concepção desse autor, o entendimento matemático depende, então, da mobilização de vários registros e, por consequência, um indivíduo aprende Matemática se ele integra, em sua arquitetura cognitiva, todos os registros necessários como novos sistemas de representação (p.16-17). 
Neste sentido, parece que mais importante do que a conversão é a coordenação entre os registros, é enxergar nos diferentes registros o mesmo objeto matemático representado. Quanto mais tranquila for esta coordenação, mais o aluno diferencia o objeto da sua representação.

Para Duval (1993), no trabalho com as representações dos objetos matemáticos, é necessário que o objeto não seja confundido com suas representações, mas que seja reconhecido em cada uma delas. Entende-se, na apropriação de um conceito matemático, que caminha-se além de sua nomeação, pois pelo menos três motivos peculiares à área matemática determinam essa superação. O primeiro motivo próprio da área é que cada conceito matemático possui referências a não objetos; portanto, os conceitos não se apoiam na realidade concreta. $\mathrm{O}$ segundo motivo é a necessidade, visto que não existem objetos de representações desses conceitos matemáticos a serem visualizados,. Por último, para o autor, a Matemática trabalha com objetos mais que com conceitos.

Um exemplo seria o trabalho com o numeral $\mathbf{3}$ ou a escrita três, que é a representação desse objeto matemático. Dentre as variadas possibilidades de representação simbólicas, icônicas e de língua escrita, é preciso que o aluno reconheça o três, por exemplo, em cada uma delas.

Figura 1 - Diversas representações do número três.

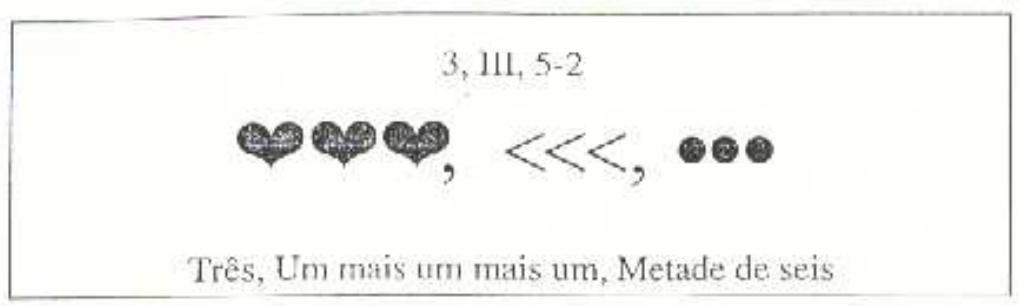

Fonte: Ponte e Serrazina, Didáctica da Matemática do $1^{\circ}$ Ciclo, Universidade Aberta, 2000.

O aluno pode escolher mudar de sentido, mudar a maneira de fazer um cálculo, por exemplo, de forma implícita ou explícita, sem suporte exterior ou com suporte nos dedos, por escrito, o que o possibilita resolver a operação utilizando os recursos disponibilizados no momento. Como o sistema escolar não valoriza essas resoluções mais pessoais, aos poucos os alunos perdem a capacidade de criar vários sentidos e passam a identificar o objeto com uma única representação e o conteúdo com sua única forma. 
Em Duval (1993), a identificação do objeto com sua representação é um paradoxo presente na área matemática, pois:

[...] de um lado, a apreensão dos objetos matemáticos só pode ser uma apreensão conceitual e, por outro lado, somente por meio de representações semióticas é possível uma atividade sobre objetos matemáticos. Esse paradoxo pode constituir um verdadeiro círculo vicioso para a aprendizagem. Como sujeitos em fase de aprendizagem, poderiam deixar de confundir os objetos matemáticos com suas representações semióticas se eles apenas podem estabelecer relações com as representações semióticas? A impossibilidade de um acesso direto aos objetos matemáticos, a não ser por meio de representação semiótica, torna a confusão praticamente inevitável. E, ao contrário, como podem esses indivíduos adquirir o domínio dos tratamentos matemáticos, necessariamente ligados às representações semióticas, se ainda não possuem uma apreensão conceitual dos objetos representados? Esse paradoxo é ainda mais forte ao se identificar atividade matemática e atividade conceitual e ao considerar as representações semióticas como secundárias ou extrínsecas. (DUVAL, 1993, apud D’AMORE, 2005, p.51)

Tal paradoxo é representado por D’Amore (2005, p. 51) no esquema abaixo:

Figura 2 - Esquema da identificação do objeto matemático com sua representação.

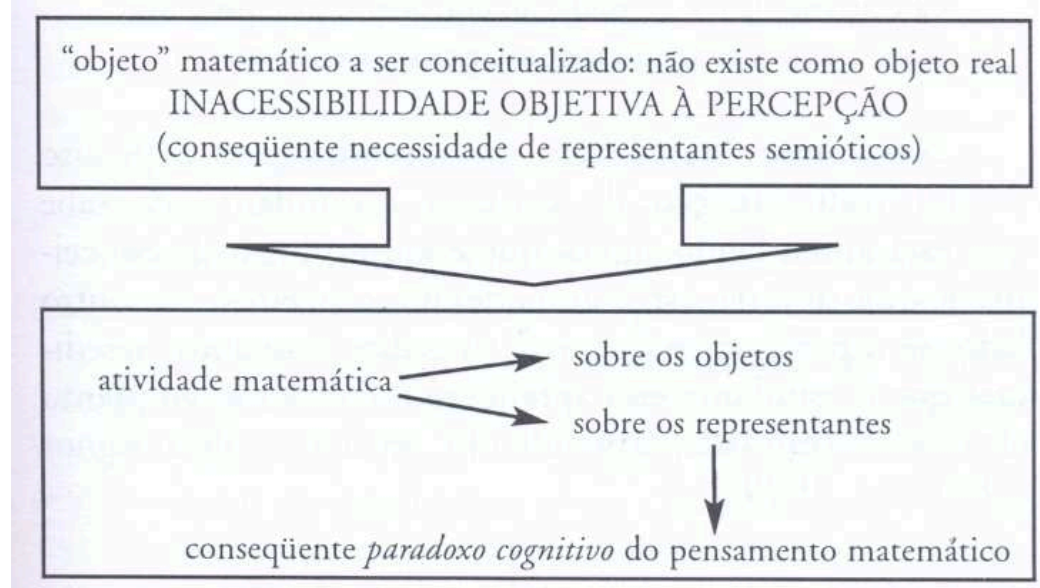

D’Amore (2005, p.52) ainda completa que "de um lado o estudante não sabe que está aprendendo signos matemáticos que estão no lugar de conceitos e que deveria estar aprendendo conceitos"; de outro lado, se o professor nunca refletiu sobre o assunto, "acredita que o estudante está aprendendo conceitos, enquanto ele está, na realidade, aprendendo apenas a utilizar signos". O autor reforça essa ideia com as palavras de Vygotsky, em "Pensamento e Linguagem" (1962), cuja impossibilidade do ensino direto de conceitos está clara: 
Como sabemos, a partir das investigações sobre o processo da formação dos conceitos, um conceito é mais do que a soma de certas conexões associativas formadas pela memória [...] é um autêntico e complexo ato de pensamento que não pode ser ensinado por meio de treinamento, só podendo ser realizado quando o próprio desenvolvimento mental da criança já tiver atingido o nível necessário [...]. O desenvolvimento dos conceitos, ou dos significados das palavras, pressupõe o desenvolvimento de muitas funções intelectuais (atenção, memória, lógica, abstração, capacidade para comparar e diferenciar)[...] A experiência demonstra também que o ensino direto de conceitos é impossível e infrutífero. Um professor que tenta fazer isso, geralmente não obtém qualquer resultado, exceto o verbalismo vazio. (VYGOTSKY, 1962 apud D’AMORE, 2005, p. 57).

A interação desenvolvida por um aluno em uma situação de ensino é um processo dialético que descarta a ilusão de uma construção linear do conhecimento, no sentido de uma sequência que vá do mais simples ao mais complexo. Brousseau (1986) diferencia, nessas interações, as situações didáticas e as situações adidáticas. Nas primeiras, estão presentes as relações entre professores, alunos e saberes específicos, e ocorrem sistematicamente para o desenvolvimento do processo de ensino e para a aprendizagem, por exemplo, de conteúdos de matemática. Nas situações adidáticas, existem fenômenos da aprendizagem que não são determinados por aspectos sistemáticos e, dessa forma, o aluno coloca em funcionamento conhecimentos em construção que não estão previstos nos contextos de ensino; ocorrem, portanto, na ausência de professores.

\section{Análise dos registros produzidos por alunos do Ensino Médio em uma questão de Matemática, sob a ótica da Teoria dos Registros de Representação Semiótica e os diferentes sentidos dos objetos matemáticos}

Diante das considerações já expressas, buscamos analisar as representações que estudantes do ensino médio de cursos da UTFPR- campus Toledo utilizaram na resolução de uma questão da prova da Olimpíada de Matemática de 2010. A questão selecionada foi a seguinte: 
Figura 3 - Questão 3 da prova da primeira fase da OBMEP-2010.

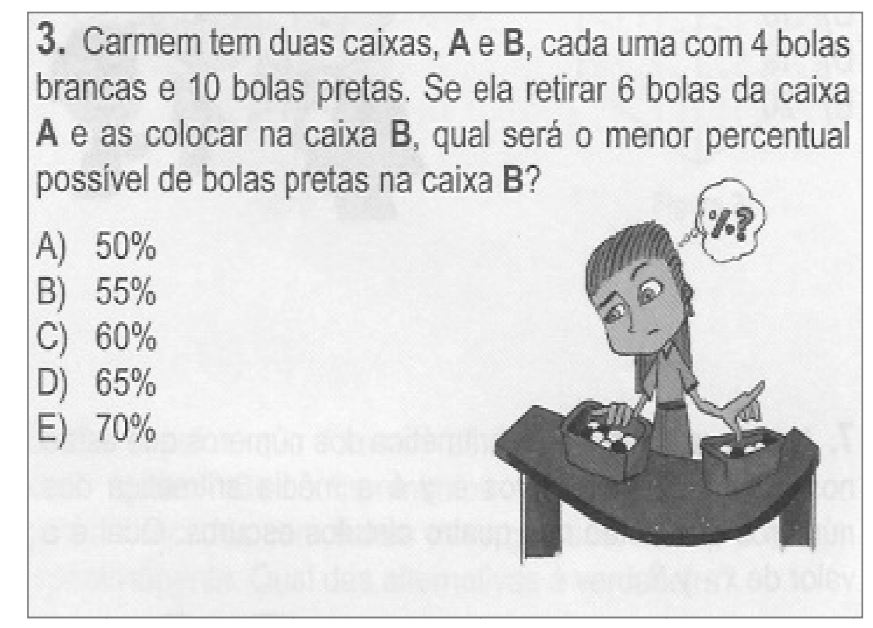

Embora não tenhamos a possibilidade de dizer, com certeza, qual o raciocínio utilizado pelos alunos ao resolverem a questão, podemos inferir, a partir dos registros produzidos por eles, quais atividades cognitivas (tratamento e conversão) foram realizadas e como tais atividades podem contribuir para a compreensão dos conceitos matemáticos presentes na resolução.

$\mathrm{Na}$ questão, os alunos precisavam calcular o menor percentual possível de bolas pretas na caixa B, depois de retirarem seis bolas da caixa A e colocá-las na B. O problema, cuja interpretação inicial é essencial, pode ser resolvido utilizando ideias relacionadas à razão e proporção. Como o que se pede é o menor percentual de bolas pretas na caixa $\mathrm{B}$, ao passar da caixa A para B seis bolas, espera-se que o menor número delas seja preto, no caso, duas. Além disso, ao calcular a razão entre bolas pretas e o total de bolas, e transformar isso em porcentagem, os alunos devem levar em consideração que, embora inicialmente 14 representassem $100 \%$ das bolas nas caixas, depois de colocadas mais seis bolas na caixa $\mathrm{B}$, o novo $100 \%$ é representado por 20 bolas. Logo, nos diferentes instantes, o todo (100\%) muda.

A fim de interpretar o enunciado, muitos alunos utilizaram o registro figural para, a partir de então, resolver a questão. No entanto, mesmo alguns alunos tendo realizado tratamentos neste registro, não conseguiram concluir a resolução por não terem realizado a conversão para o registro em que era dada a resposta da questão, o registro algébrico.

$\mathrm{Na}$ resolução da figura 4, por exemplo, o aluno apresenta a quantidade de bolas brancas e pretas em cada um das caixas, usando uma figura apenas para isso. Em seguida, desenha as caixas A e B, com a quantidade de bolas brancas e pretas final. Para representar a retirada de bolas da caixa A, realiza cortes nas bolas da representação inicial. No entanto, é possível inferir, por meio do registro escrito, que o aluno não sabia quais bolas retirar da caixa $\mathrm{A}$ e 
colocar na B, o que denota a não compreensão do enunciado - "qual será o menor percentual possível de bolas pretas na caixa B”.

Figura 4 - Tratamento no registro figural presente na resolução 1.

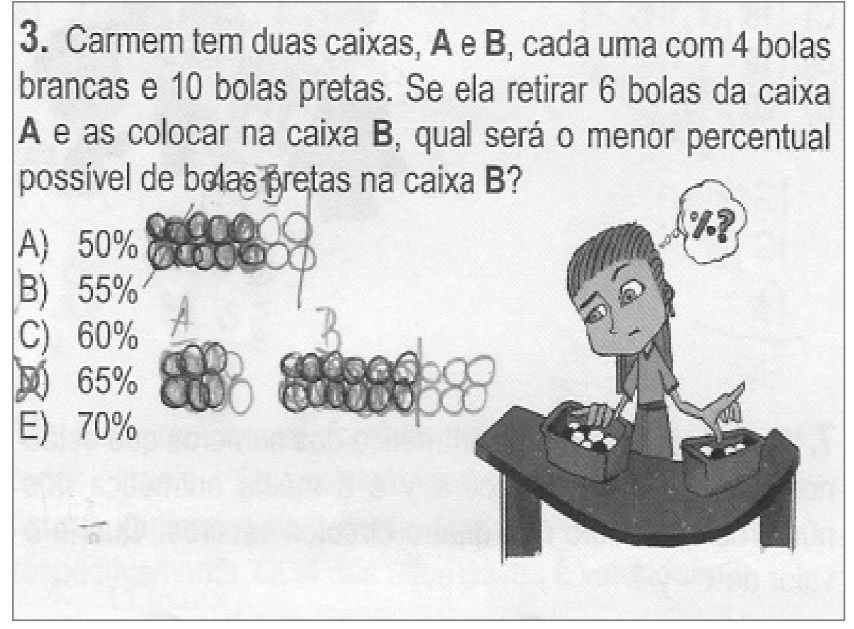

Na resolução da figura 5, o aluno também utiliza o registro figural como uma representação inicial da resolução. Mas, neste caso, diferente do exemplo anterior, além do tratamento no registro figural, o aluno realiza uma conversão para o registro algébrico, a partir da qual calcula o percentual referente a quantidade de bolas pretas na caixa B usando uma regra de três. É possível identificar, do lado direito da questão, um registro auxiliar que o aluno utiliza para resolver a operação 1200:20.

Figura 5 - Resolução 2 - registros figural, algébrico e aritmético.

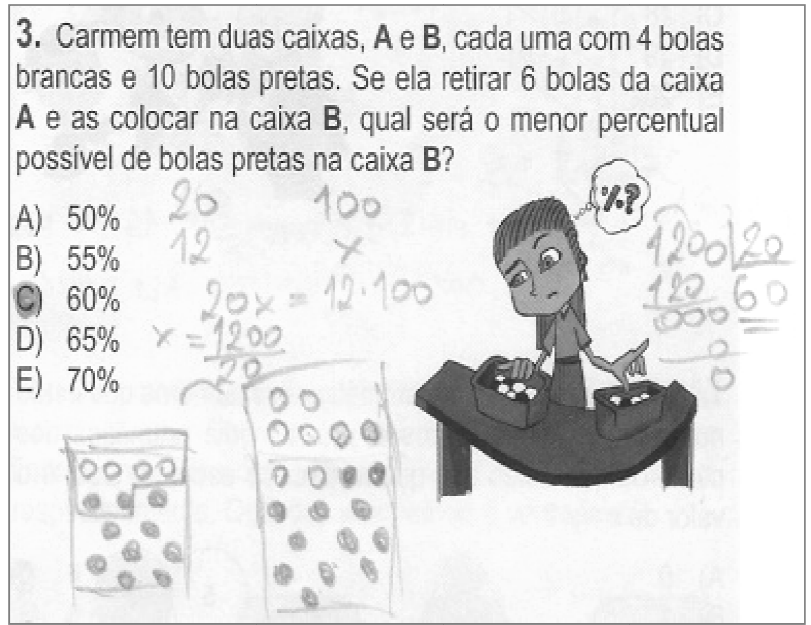


Nesta resolução, é possível inferir a seguinte sequência de atividades cognitivas, descritas na figura a seguir:

Figura 6 - Esquema relacionado ao tratamento e à conversão presentes na resolução 2.

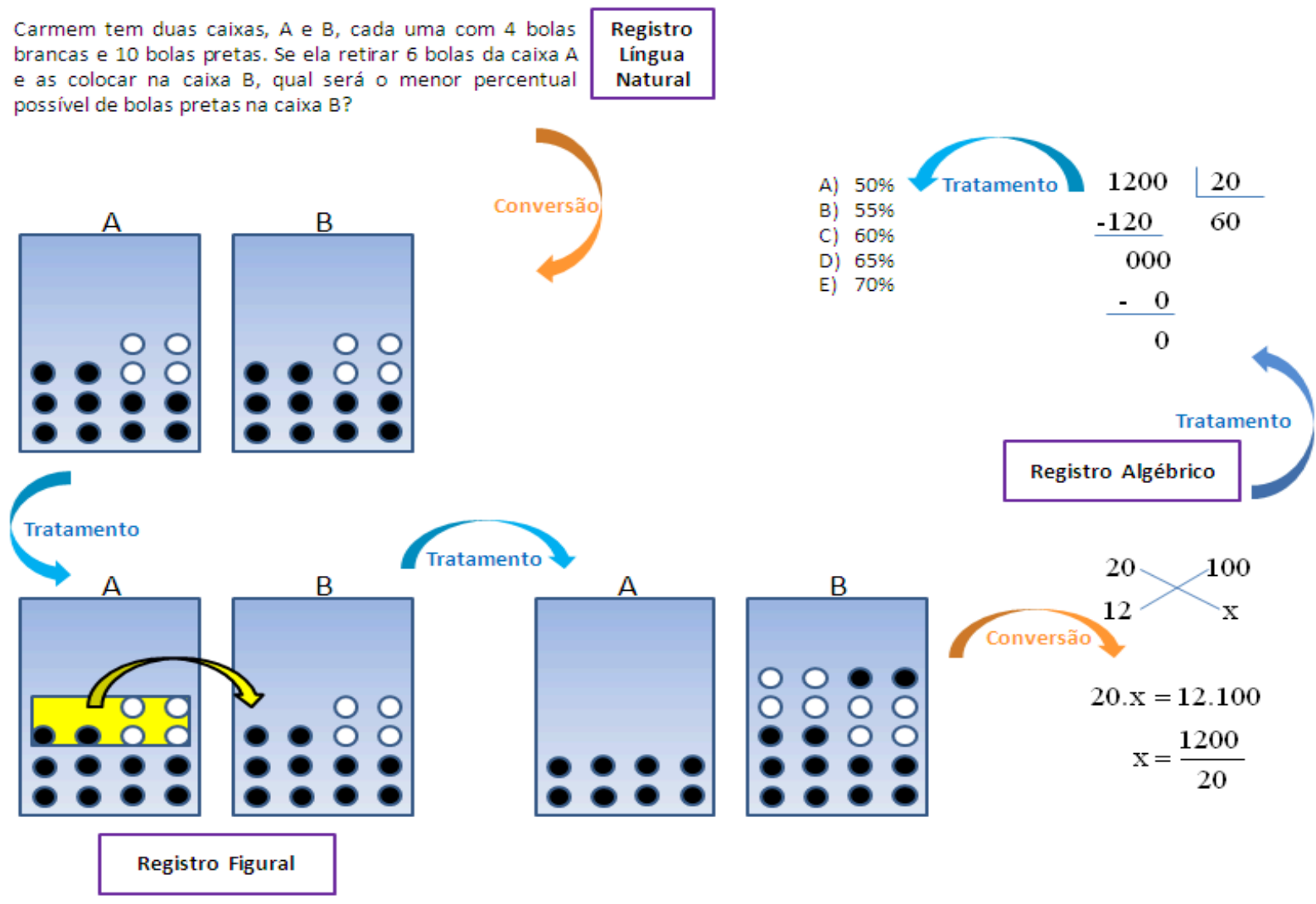

No esquema da figura, verifica-se que os tratamentos no registro figural parecem ser realizados, mantendo-se a referência constante ao enunciado da questão que, por sua vez, é dado no registro língua natural. Também são realizados tratamentos no registro algébrico. Aliás, este parece ser o registro que os alunos utilizam com maior frequência em Matemática. Segundo Garcia e Palácios (2006), ao se referirem a utilização dos registros matemáticos pelos alunos, apontam que “[...] conforme se progride em nível acadêmico cresce a preferência pela utilização de representações não gráficas (enunciados e equações) e decresce a preferência por representações do tipo gráfico (diagramas e gráficos cartesianos)” (p.47).

No entanto, segundo a teoria dos Registros de Representação Semiótica, quando se busca uma compreensão mais geral da situação matemática em estudo, é importante que tratamentos e conversões entre diferentes registros sejam atividades frequentes. 
Com relação a conversão entre registros presentes na resolução 2 da Figura 6, temos uma conversão do registro língua natural para o registro figural e outra conversão do registro figural para o registro algébrico. No entanto, ao contrário do que parece, estas conversões não se dão de modo linear, tal como se apresentam nos registros dos alunos. É diante da análise conjunta que fazem da interpretação do enunciado e das figuras construídas que decidem por um caminho algébrico que dê conta de solucionar a questão - a regra de três. Neste sentido, "[...] é necessário distinguir cuidadosamente o que sobressalta [...] em uma conversão, esta consistindo em uma simples mudança de registros ou em uma mobilização em paralelo de dois registros diferentes" (DUVAL, 2003, p.24).

Em outras resoluções, verifica-se a utilização de tratamentos no registro língua natural como meio de entender o enunciado da questão. É o caso das resoluções 3 e 4, presentes nas Figuras 5 e 6 abaixo. Nelas, os alunos retiram do enunciado informações importantes para a resolução e constroem esquemas parecidos com os apresentados por meio do registro figural anterior.

Figura 7 e 8 - Resolução 3 e 4 - Construção de um esquema em língua natural para interpretar o problema - tratamentos no registros língua natural.

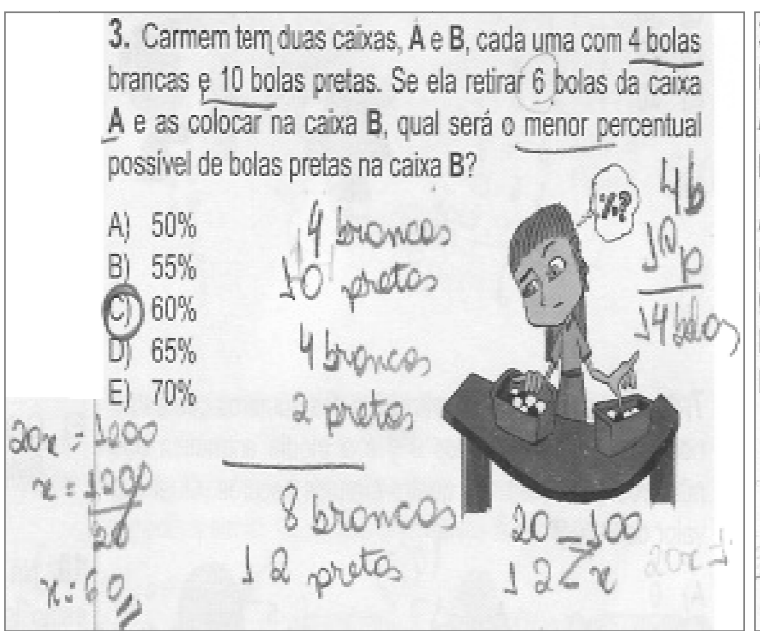

3. Carmem tem duas caixas, $\mathrm{A}$ e $\mathrm{B}$, cada uma com 4 bolas brancas e 10 bolas pretas. Se ela retirar 6 bolas da caixa A e as colocar na caixa $\mathrm{B}$, qual será o menor percentual possivel de bolas pretas na caixa B?
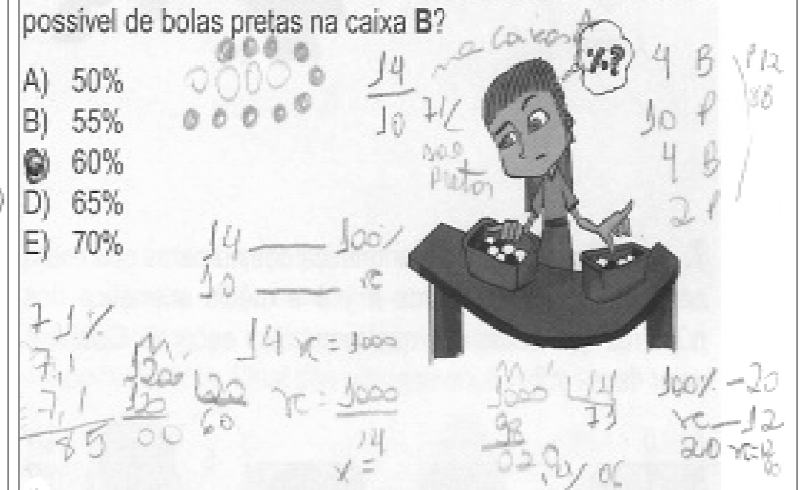

Nas resoluções acima, identificamos a seguinte sequência de tratamentos no registro língua natural: 
Figura 9 - Esquema de tratamento no registro Língua Natural presente nas resoluções 3 e 4.

Registro Língua Natural

Carmem tem duas caixas, A e B, cada uma com 4 bolas brancas e 10 bolas pretas. Se ela retirar 6 bolas da caixa $A$ e as colocar na caixa $B$, qual será o menor percentual possível de bolas pretas na caixa $B$ ?

\begin{tabular}{lll} 
& $\begin{array}{l}4 \text { brancas } \\
10 \text { pretas }\end{array}$ tratamento & $\begin{array}{l}4 \text { brancas } \\
10 \text { pretas }\end{array}$ \\
\cline { 2 - 2 } & 14 bolas & $\begin{array}{l}4 \text { brancas } \\
2 \text { pretas }\end{array}$ \\
& \\
& 8 brancas \\
& 12 pretas
\end{tabular}

Já a coordenação entre registros não implica realizar somente uma conversão do registro algébrico para o tabular e, em seguida, realizar uma conversão do registro tabular para o gráfico, por exemplo, mas compreender que todos estes registros dizem respeito ao mesmo objeto matemático e podem mesmo se complementar no sentido de que um registro pode expressar características ou propriedades do objeto matemático que não são expressas com clareza em outro registro.

Segundo Damm (1999), a coordenação entre registros de representação permite que os alunos, ao trabalharem com um determinado objeto matemático, troquem de registro de modo a escolher aquele em que os custos de tratamento e funcionamento sejam menores.

Nesta perspectiva é que apresentamos a resolução 5 da Figura 8. Nela, o aluno utiliza essencialmente a ideia de razão e proporção, e muda de registro (realiza conversões) quando percebe que os custos de tratamento e funcionamento parecem menores.

Figura 10 - Resolução 5 - Coordenação entre registros semióticos.

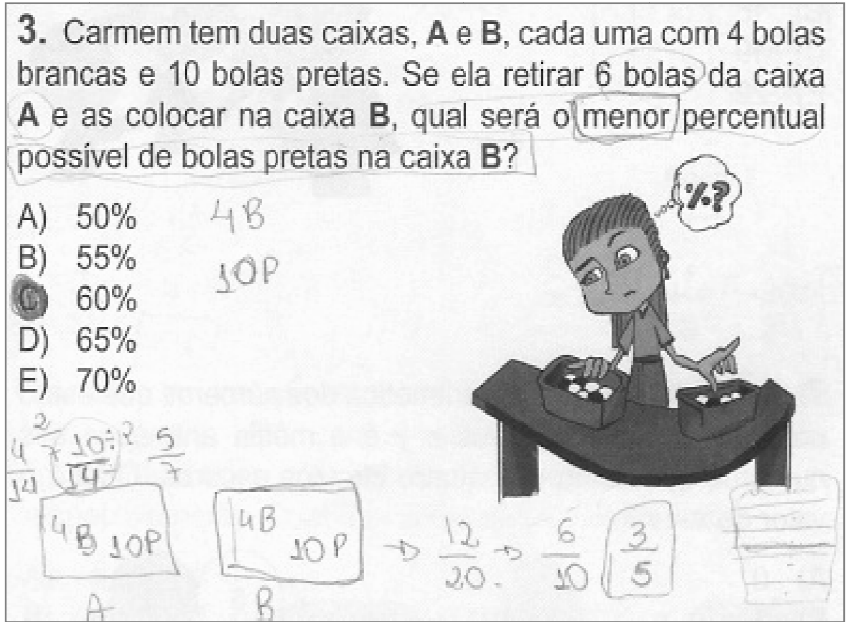


Assim como nos outros exemplos, o aluno constroi um esquema no registro figural (conversão que tem como registro de partida a língua natural) e, em seguida, utilizando da figura construída e de leituras do enunciado (veja os grifos feitos no texto da questão), conclui que o percentual de bolas pretas na caixa pode ser obtido pela razão de bolas pretas a partir do total de bolas na caixa B. Com isso, utilizando de simplificações na fração obtida, encontra a resposta 3/5 - representação que o aluno demonstra saber que se trata da resposta procurada quando a destaca. Para obter a resposta em porcentagem, o aluno projeta outra figura (no caso, um retângulo), divide-a em 5 partes e pinta 3, como se dividisse $100 \%$ em 5 partes e multiplicasse o resultado por 3, encontrando 60\%. Nesta resolução, é possível inferir a seguinte sequência de atividades cognitivas:

Figura 11 - Resolução 5 - Coordenação entre registros semióticos.

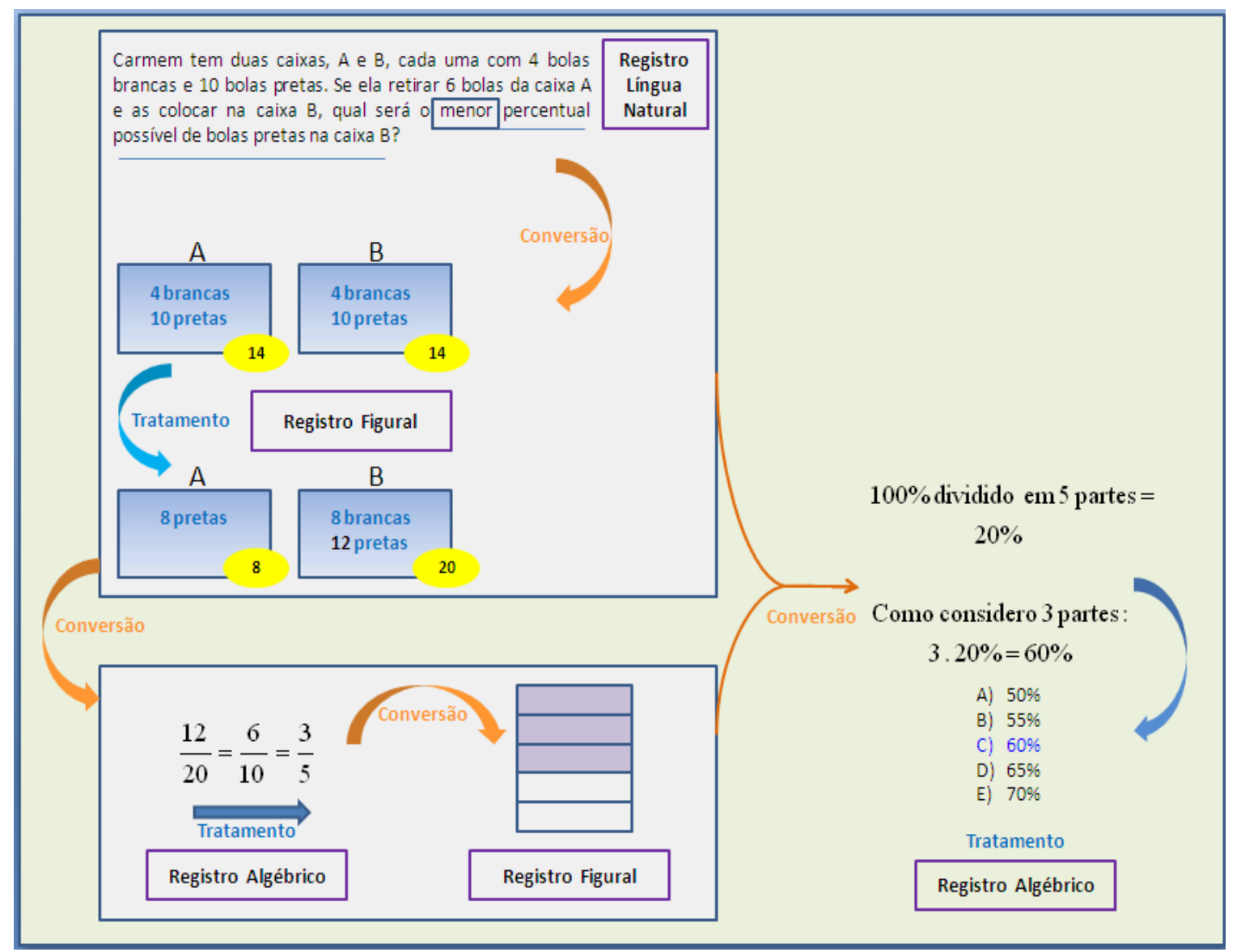




\section{Considerações finais}

Reconhecer relações entre os registros implica "perceber" que representam o mesmo objeto matemático e, à medida em que tais relações são estabelecidas, os alunos passam a diferenciar a representação utilizada do objeto matemático representado (DUVAL, 2003). O estabelecimento destas relações faz com que as conversões passem a ser realizadas com maior facilidade, uma vez que os alunos já conhecem as características próprias de cada registro. Para Duval (2003), “a capacidade de converter implica a coordenação de registros mobilizados" (p.15). Além disso, o autor afirma que o aluno deve ser capaz não somente de repetir ou de refazer, mas também de ressignificar em situações novas seu conhecimento, de adaptar, de transferir seus conhecimentos para resolver novos problemas.

Quando o aluno é considerado o autor de seu processo de aprendizagem e, diante de situações que o professor apresenta, realiza uma busca dentro de tudo o que sabe, coloca em jogo as ferramentas que possui para decidir aquilo que é mais pertinente. Assim, compreende que o saber é um meio de solucionar, de prever, de antecipar resultados, de realizar e de controlar as estratégias que utiliza para resolver as situações que lhe são apresentadas. $O$ aluno passa também a aceitar sua responsabilidade no processo, entendendo que o resultado obtido foi decorrente da escolha que fez, diante de diferentes possibilidades e, assim sendo, a relação de causalidade entre suas decisões. Dessa forma, o resultado obtido se fortalece.

D’Amore (2005) retoma os termos noesis como sendo a aquisição conceitual de um objeto e semiosis, a representação realizada por meio de signos. Os estudantes, ao decidirem mudar o registro semiótico, também devem mudar a representação semiótica utilizada: não existe noesis sem semiosis, além da semiosis ser o primeiro passo para o alcance da noesis. Essas considerações podem, ainda, ser assim expressas: os estudantes representam um conceito em um dado registro, conseguem tratar tais representações no interior de um mesmo registro e fazem a conversão de um dado registro para outro. São aspectos indissociáveis do processo de aprendizagem, visto que é próprio do pensamento humano o uso de diversos registros de representação semiótica, bem como a criação e o desenvolvimento de novos sistemas semióticos demarcarem o progresso do conhecimento em várias áreas.

Neste sentido, a Matemática passa a assumir seu importante papel social, torna-se autoria de muitos, superando a visão de transmissão e reprodução de verdades únicas e acabadas. É um desafio, pois o espaço escolar valoriza ainda essa transmissão e reprodução do conhecimentos em fatos isolados, fragmentados. "O conhecimento do fato não tem valor senão em função 
dos processos de descoberta que permitiram que ele fosse estabelecido (PIAGET, 1998, p. $56) "$

\section{Referências}

BROUSSEAU, G. Fondements et méthodes de la didactique des mathématiques. In: Recherches em Didactique des mathématiques, 7/2, 1986, p. 33-115.

DAMM, Regina F. Registros de Representação. In: MACHADO, Silvia Dias Alcântara. Educação Matemática: uma introdução. São Paulo: EDUC, 1999, p.135-154.

D’AMORE, B. Epistemologia e Didática da matemática. São Paulo: Ed. Escrituras, 2005.

DUVAL, R. Registres de représentation sémiotique et fonctionnement cognitif de la pensée. Annales de Didactique et de sciences cognitives, 5, Estrasburgo, 1993.

Registros de Representações Semióticas e Funcionamento Cognitivo da Compreensão em Matemática. In: MACHADO, Silvia D. A. Aprendizagem em Matemática: Registros de Representação Semiótica. Campinas: Editora Papirus, 2003, p.1134.

GÀLVEZ, Grécia. A didática da matemática. In: PARRA, C.; SAIZ, I. (org). Didática da matemática: reflexões psicopedagógicas. Porto Alegre: Artmed, 1996.

GARCIA, José J. G.; PALACIOS, Francisco J. P. ¿CCómo usan los professores de Química las representaciones semióticas?. Revistra Electrônica de Enseñanza de las Ciências. v. 5, n. 2, 2006. Disponível em: <http://www.saum.uvigo.es/reec/ volumenes/volumen5/ART3_Vol5_N2.pdf>. Acesso em: 10 de outubro de 2006.

JAHN, Ana P.; KARRER, Monica. Transformações lineares nos livros didáticos: uma análise em termos de registros de representação semiótica. Educação matemática em revista, Recife/PE, Ano 11, n.17, p.16-28, 2004.

PANIZZA, M. Reflexões sobre o ensino da matemática. In: PANIZZA, Mabel. Ensinar matemática na educação infantil e nas séries iniciais- análises e propostas. Porto Alegre: Artmed, 2006.

PIAGET, Jean. Sobre a Pedagogia- textos inéditos. São Paulo: Casa do Psicólogo, 1998.

PONTE, J.P.; SERRAZINA, L. Didáctica da Matemática do $1^{0}$ Ciclo. Lisboa: Universidade Aberta, 2000.

VERGNAUD, G. El niño, las matemáticas y la realidad. Problemas de la ensenãnza de las matemáticas en la escuela primaria. México: Trillas, 1991.

A trama dos campos conceituais na construção dos conhecimentos. Revista do Gempa, 4, p 9-19, 1996. 